\title{
ECONOMIC ASPECTS OF OCCUPATIONAL INJURIES IN MINING
}

\author{
Jelena Ivaz ${ }^{1}$, Dejan Petrović ${ }^{1}$, Aleksandra Fedajev ${ }^{1}$, Vitomir Milić ${ }^{1}$, Saša \\ Stojadinović ${ }^{1}$ and Pavle Stojković ${ }^{1}$
}

\begin{abstract}
Mining is often the subject of a study of safety and health at work as one part of industry that carries the greatest risk of injury. The most of these analyses are directed on studying the method of injuries of workers and procedures that can prevent injury. Financial expenditures resulting from injuries of workers in Bogovina coalmine which occurred in 2016 are analyzed in this paper. Injury costs were processed based on the available data: compensations of the insurance companies to the injured workers, gross salaries of injured workers and similar. Within these data, the "cost of one work day lost" (COWDL) is defined. Comparison of the COWDL, based on qualification structure of the injured worker and the severity of the injuries, was performed. Also, an impact analysis of expenditures related to indemnity related to injuries at work to mine operational costs were carried out.
\end{abstract}

Keywords: mining; injuries at work; financial expenditures;

\section{INTRODUCTION}

The mines have specific and very difficult working conditions, especially those with underground exploitation of coal. Such conditions require the application of precise instructions in the field of safety and safety at work. Special accent was given to strict discipline, implementation, usage and control of prescribed occupational safety measures. But despite these measures, it often happens that a worker is injured, experienced a trauma, permanent disability or in the worst case, an accidental situation with a fatal injury. The consequence of these accidents is, in almost all cases, the absence of an injured worker from work. In addition to the absence of workers, the consequences can also be: temporary or permanent disability of worker, production delays, financial and medical expenses (direct and indirect), as well as other expenditures that are paid to the funds Republic of Serbia. The study of the structure of these expenditures is very complex, especially in the case of injuries that result in a permanent disability of workers or require a long treatment of workers until their return to work.

${ }^{1}$ University of Belgrade - Technical Faculty in Bor Emails: dpetrovic@tfbor.bg.ac.rs; 
The economic consequences of workers' injuries in the coalmines were analyzed in this paper. In the paper also were proposed the bases for the analysis of total expenditures for the needs of the mine, which could be uniformly applied to all mines. Expenditures resulting from absence of worker which directly burden the company's operations were analyzed as well as payment of insurance premium by insurance companies. The analysis is given by the fact that these expenditures were presented by "cost of one work day lost" (COWDL). This parameter is considered from the aspect qualification structure of the employee's and the severity of the injury. The qualification structure is a very important aspect of considering of worker injuries in mining, as the injuries at the work of employees with different qualifications is reflected differently on the business. Injury of workers, for example, the workplace geologist has a higher value because the salaries of these workers are higher. But since they are not usually direct production workers, it can say that the indirect consequences of injury are less because their absence does not require the engagement of a new employee in that period. The economic consequences of injuries of workers which are directly involved in production are higher because the production process requires the engagement of new workers or as a consequence can be a lower production, (Spasić, 2003). Injuries can be divided into: fatal, severe and light. The severity of the injury is also an important parameter for the analysis of injuries at work, it would be realistic to expect heavy injuries to cause higher expenditures than an easy one, but this is often not the case.

\section{SAFETY AND HEALTH AT WORK IN MINING}

The most common definition of occupational safety and health protection at work, OHS, is it a set of measures and activities aimed at creating such conditions of work that provide safety at work, to prevent and eliminate the risks and damages that can cause occupational injuries, illnesses and damage to the health of employees at work or in connection with work, as well as the protection of life, health and working capacity of employees, (Štajner, 2015).

The OHS is an important segment of the study of many disciplines such as engineering, economics, sociology, medicine and etc. The great influence on the safety climate in some companies also has the relationship of the company's management to this issue. Clearly defined measures of the OHS that are consistently implemented can greatly reduce the occurrence of injuries. The legal aspect related to employee injuries is clearly defined by the Labor Law, the Safety and Health Protection of Employees at work and other regulations governing this field. It is important to point out that the more frequent occurrence is the fact that the employee start a legal proceed against the company, in terms of compensating for the injury suffered, and this expenditure could also be classified as a legal component. The medical aspect is important for the procedure and costs of treatment of injured worker, and recovering workers ability. This is a very 
complex domain that follows the expenditure of the Republic Health Insurance Fund. The technical factor that is of the greatest intent for employers implies all the measures that must be taken to ensure a smooth return to the established mode of production, repair of the machinery in the event of damage, restart of production, replacement workers, etc., (Spasić, 2003; Anđelković, 2012; Moller, 2006).

\section{ECONOMICAL ASPECTS OF SAFETY AND HEALTH AT WORK}

When risky event was happened, a regular procedure involves looking at each individual injury in order to determine the causes of injuries and eliminate possible shortcomings in production technology, mode of operation, machinery itself, etc. Periodic analysis of the causes of injuries in mines is a duty of all services of the OHS and is done monthly, quarterly and annual. In addition to this analysis, it is necessary to conduct an analysis of the financial expenses and losses that this injury causes in the company's financial status. In this regard, the economic effects of the resulting work injuries in the Bogovina coalmine will be analyzed below for one year period.

\subsection{Structure of financial expenditure of injuries at work}

Injuries at work have numerous negative effects on the business of mining companies, but this paper deals with only those who can financially express themselves and who have frequently appeared. There are accidents where in addition to workers' injuries, there is a larger number of consequences, for example, the production is stopped on a machine or in a system until the inspection or police insight at the scene of the accident, if injury is fatal. The company also has expenditures and losses. Accidental situations occur where, due to improper work of the injured person, he can produce hazardous situation for his colleagues and caused, say, a collective injury or damage tools and machines. Only those financial indicators, such as expenditures that are the direct consequence of the injury and which each injury carries are analyzed in this paper.

Occupational injury costs have a complex structure and vary from country to country. In the paper they are divided into three groups:

1. the first group includes all those expenditures related to the obligations of the employer towards the employee and the losses in the production process, such as:

- salary of employee,

- required insurance of employees by the employer in case of injury,

- losses in the production process as result of the absence of workers from work,

- additional expenditures for medical checkup in the event that the absence of workers is longer than 6 months, 
- expenditure on funerals and scholarships for children in the event that an accident result is fatal injury,

- compensation in case that a worker sues a company for traumas caused of injury,

- others material expenditures: damage to machinery, stops of production, losses of mineral resources etc.

2. in the second group of expenditures are costs related to the treatment of workers:

- expenditures of medical services,

- expenses of a hospital day, surgery or other medical intervention,

- expenditures for further treatment of drugs, bandages, therapies, analyzes,

- expenses for transport of injured worker to the treatment institution,

- expenditure on commission reviews,

- medical aid expenditures,

- expenditures of postoperative care, physical therapy, spa treatments,

- expenses for treatment abroad,

3. and the third group of expenditures includes those related to joint liability by the employer and the state, and these are:

- pension and disability insurance of the employed worker,

- expenditures related to the payment of the extra paid work period are not paid during the absence from work,

- insurance of an employee in case of loss of work,

- health insurance of workers,

- income tax, etc., (Milošević and Jovanović, 2016).

The assessment of the effects of injuries at work requires a detailed and comprehensive analysis of all available parameters because the structure of expenditures is very complex.

\subsection{A review of the injuries in Bogovina coal mine in 2016}

The Bogovina coalmine operates within Public Enterprise Resavica and deals with the underground exploitation of brown coal. The mine has also implemented a certified OHSAS 18001 standard that has created the conditions for better access to safety and occupational safety issues. The Risk Assessment Act examined all working positions in a company for which special working and medical conditions that the worker must fulfill. In this mine 21 injuries occurred during the 2016.In all cases, an injured worker was absent from work for more than three consecutive working days. In Bogovina mine were occur three heavy and eighteen light injuries for the analyzed period, Table 1 . In this Table injuries that happened in 2016 according to the severity of the injury and the qualification structure of the workers are shown. All displayed injuries are used as input data to understanding the problem described in the paper. 
Table 1 Injuries in Bogovina coalmine that happened in 2016, (Report, 2016 a).

\begin{tabular}{|c|c|c|c|c|}
\hline No. & $\begin{array}{l}\text { Severity of } \\
\text { injury }\end{array}$ & Site of injury & Injured body part & Qualification \\
\hline 1 & HEAVY & Outside & leg & Qualified miner \\
\hline 2 & HEAVY & Mine & head & Qualified miner \\
\hline 3 & HEAVY & Mine & shoulder & Nonqualified \\
\hline 4 & LIGHT & Mine & arm & Nonqualified \\
\hline 5 & LIGHT & Mine & back & Semi qualified miner \\
\hline 6 & LIGHT & Mine & leg & Nonqualified \\
\hline 7 & LIGHT & Mine & shoulder & Semi qualified miner \\
\hline 8 & LIGHT & Mine & body & Qualified electrician \\
\hline 9 & LIGHT & Mine & finger & Nonqualified \\
\hline 10 & LIGHT & Mine & finger & Nonqualified \\
\hline 11 & LIGHT & Mine & shoulder & Geological engineer \\
\hline 12 & LIGHT & Mine & finger & Nonqualified \\
\hline 13 & LIGHT & Mine & leg & High school, blaster \\
\hline 14 & LIGHT & Mine & leg & Qualified machinist \\
\hline 15 & LIGHT & Outside & leg & Qualified processing worker \\
\hline 16 & LIGHT & Mine & leg & Qualified miner \\
\hline 17 & LIGHT & Mine $\mathrm{J}$ & head & Semi qualified miner \\
\hline 18 & LIGHT & Mine & shoulder & Qualified miner \\
\hline 19 & LIGHT & Outside & arm & Qualified machinist \\
\hline 20 & LIGHT & Mine & shoulder & Semi qualified miner \\
\hline 21 & LIGHT & Mine & finger & Nonqualified \\
\hline
\end{tabular}

It is important to note that all the data used in the table shown in Figure 1, obtained directly from the employer. So, this analysis can be used to look at expenditures within the needs of this mine. Other expenditures and losses in production that are inevitable when some injuries occur are not counted as there is no possibility for these data to be obtained from the Insurance Fund bases. The real picture of expenditure would have to take into account the data related to the production stops, medical expenses, transport of injured worker, accidents, etc. as described above. The advantage of such approach by looking at the accompanying costs is that the employer can formulate a questionnaire within his company and treat it separately for each injury.

\subsection{Analysis of injury costs in bogovina mine}

The main indicators related to expenditure of injuries at work occurred in Bogovina coalmine in 2016 are shown in Table 2. The displayed data is sorted into 8 columns as follow: 
1. The insurance premium paid by an insurance company, at places where the value of RSD 0.00 injured worker has not applied for the payment of insurance,

2. Total number of working days spent on sick leave,

3. Worker coefficient, which depends on his / her qualification and position, significantly different coefficients for outside and underground workers, surface workers have less work coefficients because the act of risk assessment these jobs are not characterized as high risk,

4. Expenditure for injured based on earnings, which are obtained by multiplying the coefficient, the value of the points(it is the same for all workers136. 89 RSD) and the number of days spent on sick leave. The value of the points is prescribed by the ministry and is the same for all workers, (basic cost of work hour).

5. Annual leave reimbursement total, obtained by multiplying annual leave reimbursement valueper day (it is the same for all workers 89.70RSD) with the number of days spent on sick leave,

6. Total expenditures based on earnings and annual leave reimbursement, obtained as a sum of the previous two columns,

7. Sum of expenditures, which represent the sum of total expenditures based on earnings and annual leave reimbursement and paid insurance,

8. Cost of one work day lost (COWDL) is obtained when the previous column is divided by the number of days on sick leave, 
Table 2 Expenditures of injuries in Bogovina coalmine, (Report, 2016 b)

\begin{tabular}{|c|c|c|c|c|c|c|c|}
\hline $\begin{array}{l}\text { Insurance } \\
\text { premium }\end{array}$ & $\begin{array}{c}\text { Total } \\
\text { days of } \\
\text { sick } \\
\text { leave }\end{array}$ & $\begin{array}{l}\text { Worker } \\
\text { coefficient }\end{array}$ & $\begin{array}{l}\text { Expenditure } \\
\text { for injured } \\
\text { based on } \\
\text { earnings }\end{array}$ & $\begin{array}{c}\text { Annual leave } \\
\text { reimbursement } \\
\text { total }\end{array}$ & $\begin{array}{c}\text { Total } \\
\text { expenditures } \\
\text { based on } \\
\text { earnings and } \\
\text { annual leave } \\
\text { reimbursement }\end{array}$ & $\begin{array}{c}\text { Sum of } \\
\text { expenditures }\end{array}$ & $\begin{array}{r}\text { Cost of one work } \\
\text { day lost(COWDL) }\end{array}$ \\
\hline 500.00 & 52 & 2.032 & 115715 & 4664 & 120379 & 120879 & 2325 \\
\hline 19800.00 & 67 & 2.032 & 149094 & 6010 & 155104 & 174904 & 2611 \\
\hline 1600.00 & 20 & 2.865 & 62750 & 1794 & 64544 & 66144 & 3307 \\
\hline 0.00 & 14 & 2.032 & 31154 & 1256 & 32410 & 32410 & 2315 \\
\hline 50800.00 & 137 & 2.197 & 329619 & 12289 & 341908 & 392708 & 2866 \\
\hline 33600.00 & 19 & 2.527 & 52580 & 1704 & 54284 & 87884 & 4625 \\
\hline 1800.00 & 20 & 2.770 & 60670 & 1794 & 62464 & 64264 & 3213 \\
\hline 5000.00 & 47 & 2.329 & 119875 & 4216 & 124091 & 129091 & 2747 \\
\hline 500.00 & 6 & 1.722 & 11315 & 538 & 11853 & 12353 & 2059 \\
\hline 5900.00 & 55 & 2.527 & 152205 & 4934 & 157139 & 163039 & 2964 \\
\hline 1200.00 & 13 & 2.197 & 31278 & 1166 & 32444 & 33644 & 2588 \\
\hline 0.00 & 13 & 2.527 & 35976 & 1166 & 37142 & 37142 & 2857 \\
\hline 1400.00 & 82 & 1.542 & 138471 & 7355 & 145827 & 147227 & 1795 \\
\hline 1900.00 & 21 & 2.197 & 50526 & 1884 & 52409 & 54309 & 2586 \\
\hline 2100.00 & 22 & 2.032 & 48956 & 1973 & 50930 & 53030 & 2410 \\
\hline 68600.00 & 21 & 2.032 & 46731 & 1884 & 48615 & 117215 & 5582 \\
\hline 14600.00 & 172 & 2.032 & 382749 & 15428 & 398177 & 412777 & 2400 \\
\hline 0.00 & 16 & 2.197 & 38496 & 1435 & 39931 & 39931 & 2496 \\
\hline 13500.00 & 60 & 2.032 & 133517 & 5382 & 138899 & 152399 & 2540 \\
\hline 2900.00 & 32 & 2.197 & 76991 & 2870 & 79862 & 82762 & 2586 \\
\hline \multirow[t]{3}{*}{3300.00} & 13 & 2.329 & 33157 & 1166 & 34323 & 37623 & 2894 \\
\hline & & $\begin{array}{l}\text { Average } \\
\text { value }\end{array}$ & 87576 & 3371 & 90947 & 100489 & 2490 \\
\hline & & Total & 2101824 & 84281 & 2273681 & 2512223 & \\
\hline
\end{tabular}

Average days lost in Bogovina mine are 42,5 per injury. Comparing to Novi Sad Health center data, 13,3-17,1, Raška district 21,37, Novi Pazar town 23,5, Kraljevo 22, Nedić (2012), this value is very high. According to Nedić (2012) in Montenegro for 2007 average days lost was 82, from 71 days lost in Šavnik to 111 in Rožaje town.

From the analyzed data in Table 2, in the third column it can be seen that the most days of sick leave was spent by a worker who suffered a light hand injury 172. This is unexpected. It would be logical that the workers with heavy injuries are longer on sick leave. From the detailed analysis of a mentioned worker with light hand injuries it can be seen that it is an underground non-qualified worker. By inspecting the ID of this worker, it was found that during 2016, he suffered another injury when he injured his finger on his hand and spent a total of 67 days at sick leave, which is total of 239 days at sick leave for 2016. Such cases are not rarity, but the laws in Serbia are not efficient and do not work out such workers. It is obviously that is misuse of sick leave by workers supported by doctors. Such cases are not rarity, but the laws in the Serbia are not efficient and do not take measures to reduce such phenomenon. 
An analysis of the remaining injuries shows that a worker who has suffered a heavy injury, a leg fracture, has 137 days of sick leave, while a worker who had a leg fracture, a heavy injury also, has only 19 days of sick leave. It can be explained by the fact that every fracture is categorized as a heavy injury never mind if they are not the same.

The shortest on sick leave was a worker who suffered a light injury to his leg.

Expenses for injuries at work are calculated on the basis of the number of days on sick leave and depending on the amount of the calculated salaries of workers. A more realistic picture is obtained when it's calculated the COWDL because of this direct proportionality. The value of this parameter in 18 cases ranges from 2000 to 3000 dinars, the average value of 2490 dinars, fig. 1. Extremely high value is 5582 and 4625 dinars, which refers to a heavy injury to the leg of a worker who spent only 19 days on sick leave and another heavy injury to workers who spent only 21 days at sick leave. A worker who also suffered a heavy injury and was 137 days at sick leave has a COWDL value of 2866 dinars, which is a little above the average. These high values can be explained that in first 30 days at sick leave in the salary calculation are involved and bonus for night shifts work. The minimum value of the COWDL is 1795 dinars and it was obtained for an injury to the outside worker who spent 82 days in sick leave.

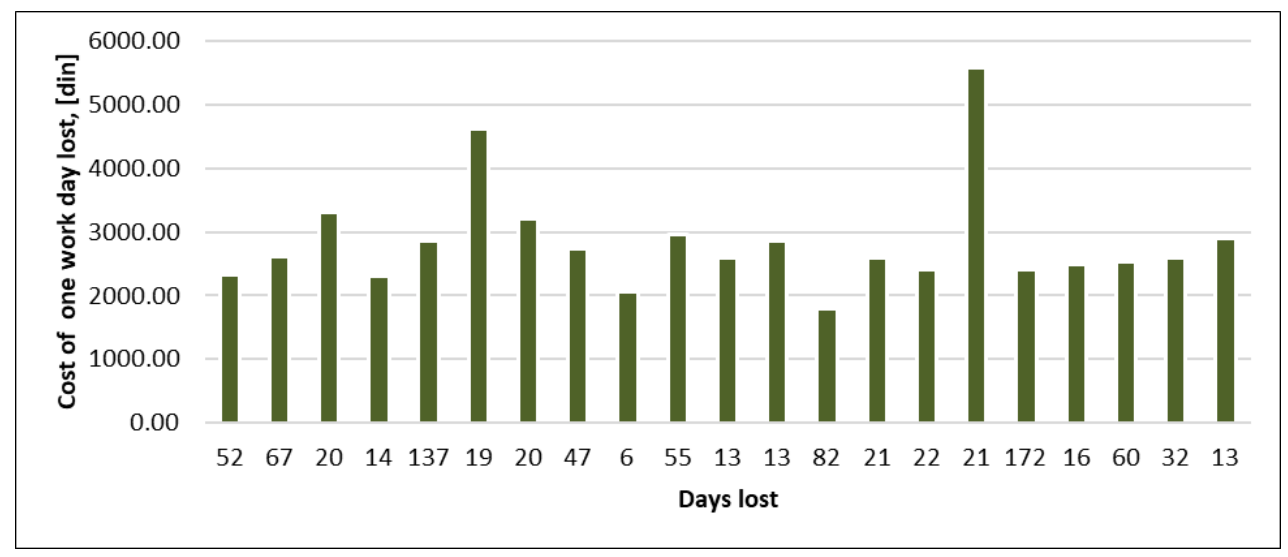

Figure 1 Cost of one work day lost

If, on the basis of the qualification the expense of injury is observed, there is an evident difference between the outside and the underground workers. It depends of coefficient of worker. For example, a worker on surface who had 6 days of sick leave and injured his arm and a worker on surface with less qualification who spent 82 days of sick leave, both have a COWDL of about 2000 dinars, i.e., 1795 and 2059, which is below the median minimum, while underground workers with the same injuries and the same qualification, they have a value of 2500 dinars, 2611 and 2400 dinars. Of course, this is the value of a coefficient of work that directly affects the value of expenditure for workers income. 
Comparative analysis of worker with high qualifications and non-qualified worker who were at sick leave the same number of days and injured the same part of the body, but the injuries are categorized different: heavy and light, shows the following: expenditures on the basis of earnings are higher for worker with higher education, but the employee who suffered heavy injury has realized a higher amount of insurance and his COWDL for 2275.00 dinars is higher than the graduated engineer.

\subsection{Economic effects of injury at work in Bogovina mine}

In recent years, the mine has been facing with numerous problems in its development, and without state support its further functioning would be questioned. In order to examine the operating of this public enterprise in the past period, Table 3 shows the income statement for the period 2015-2016.

Table 3 Incomes of Bogovina coal mine for the period 2015-2016 (Report, 2015 and 2016).

\begin{tabular}{lll} 
& $\mathbf{2 0 1 5}$ & $\mathbf{2 0 1 6}$ \\
\hline Total incomes & $383,533,945.39$ & $466,447,136.84$ \\
Incomes from production & $374,271,624.14$ & $458,963,928.06$ \\
Incomes from state subventions & $3,220,265.52$ & 0,00 \\
Non-operating and extraordinary income & $2,859,713.19$ & $4,237,810.27$ \\
Internal income & $3,182,342.54$ & $3,245,398.51$ \\
Expenses total & $506,164,534.83$ & $504,470,516.39$ \\
Operating expenses & $400,458,756.13$ & $407,255,735.98$ \\
Material costs & $57,330,240.54$ & $25,678,259.22$ \\
Employees costs & $287,766,531.06$ & $306,738,848.17$ \\
Costs of prodiction services & $3,644,230.45$ & $3,292,850.91$ \\
Costs of amortization and reservation & $46,850,324.29$ & $35,586,390.27$ \\
Non-material costs & $4,867,429.79$ & $3,577,334.81$ \\
Financial expenses & $30,296,273.40$ & $4,235,891.90$ \\
Other expenses & $6,623,227.17$ & $3,809,102.88$ \\
Internal expences & $68,786,278.13$ & $89,169,785.63$ \\
\hline FINANCIAL RESULT & $\mathbf{- 1 2 2 , 6 3 0 , 5 8 9 . 4 4}$ & $\mathbf{- 3 8 , 0 2 3 , 3 7 9 . 5 5}$ \\
\hline
\end{tabular}

What is evident from Table 3 is that this mine in the observed two years period is operating with a loss, and in 2016, the loss was 3.2 times lower than in 2015.Total incomes of enterprises increased by $21.62 \%$ in 2016 , whereby, as in the previous year, subsidy income had the highest share in total business income (as much as $88.7 \%$ ) and overall incomes in general $(87.28 \%)$. What further get a worst the situation of this company's business is the fact that compared to the previous year, the share of incomes 
from coal sales, as their main activity are lowered because of decreasing of production. Participation of income from coal sale in 2015 amounted to $15.35 \%$, and in 2016 it was reduced to $10.48 \%$.On the other hand, total expenditures were reduced by only $0.33 \%$.It is interesting to note that in the structure of operating expenses employees' costs have the highest amount. This participation amounted to $75.32 \%$ in 2016 and is higher by $3.46 \%$ compared to the previous year.A significant part of these costs are the costs of sick leave paid by a company for an average sick leave of up to 30 days, and after 30 days are paid by the state.The total sick leave payments paid by this company in 2016 amounted to $1,167,157.35$ dinars or $0.38 \%$ of the total costs. Although this increase seems to have a slight effect, it would reduce the loss to $36,856,222.2$ dinars. In addition to increasing the costs of employees, due to the injuries and the lack of employees, there has been a significant reduction in production and total incomes.

\section{CONCLUSION}

From the analysis of the injuries, it can be seen that the length of the sick leave depends not only on the severity of the injury, but also depends on the habits and attitudes towards the work of the worker and the doctor.The injuries that were manifested by a smaller number of lost days have a higher COWDL, but in the overall score, the most costly workers are those who have been in long-term at sick leave because the company has losses in the production process all the time because of a lack of labor.Qualification of worker has an impact in the situation when the employee was in a long-term at sick leave with the same severity of injuries, while in the case of injuries where the absence from work is shorter, it loses its relevance, and the severity of the injury has a greater impact on the COWDL due to the participation of the insurance.

This approach to the analysis of the cost of injuries that occurred in the mines, allows each injury and each worker to be thoroughly analyzed.It is necessary to form a database where for each injury when it happened they would fill in the data that was then available to easier create the costs calculation of injury.Generally, it is necessary to establish detailed records and analysis of data on incurred injuries and expenses incurred by them for the employer.It is certainly necessary to implement increased control and determine why some workers have a large number of lost days than expected and also need to working on increasing of safety in mines.

\section{REFERENCES}

SPASIĆ D. (2003) Economics of Occupational Safety. Grafika „Galeb“, Niš.

ŠTAJNER B. (2015) Manual for the training of occupational safety specialists. Zitel.

MOLLER N. (2006) Safety and Decision-making. Stockholm. 
MILOŠEVIĆ N. and JOVANOVIĆ D. (2016) Risk management in handling conveyors Tehnika-Menadžment, 66, pp. 298-303.

ANĐELKOVIĆ B. (2012) Occupational safety in the context of modern technological changes, Inženjerstvo zaštite, vol. 2, pp. 47-53.

REPORT, 2016 a. RM BOGOVINA (2016) Annual report on safety and health at workWork injury and sick leave analysis for the 2016.

REPORT 2015 and 2016. (2016) Extract from the financial report for 2015 and 2016. RMU Bogovina.

REPORT (2016b), Extract from the calculation of workers salaries in RMU Bogovina for 2016.

NEDIĆ O. (2012) Analysis of five year morbidity absenteeism employees in one health center- Iindicators of temporary inability to work, Zdravstvena zaštita, 4/2012. pp. 23-33. 